\title{
Successful Fusion Of Information Systems Concepts With Complementary Technical Skill
}

Shannon M. Fitzgerald, (E-mail: shash123@aol.com), Saint Joseph’s University Nicholas John Robak, (E-mail: nrobak@sju.edu), Saint Joseph’s University

\begin{abstract}
This paper addresses the integration of technical skills with information systems concepts required in an introductory MIS course, specifically focusing on the laptop inclusion initiative at our university. We will show the working relationship between the concepts and application segment of MIS, and how a laptop inclusion program combined with the use of e-Learning methodologies successfully combine the two.
\end{abstract}

\section{Introduction}

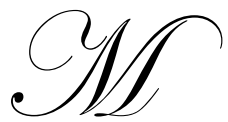

anaging students, technology and system concepts knowledge challenges MIS educators. Cohesively blending MIS themes is a pedagogic conundrum. It is our responsibility to familiarize business students with basic computing skills, the building blocks of PCs, and application software in order to send them onto future business school endeavors with a practical understanding of the what's and how tos of information systems. The separate elements of content and technical ability create an academic quandary. How do we effectively fuse the concepts of information systems with a hands-on workable knowledge of technical aptitude?

\section{Adapting to Change}

"Embedding a language in a course drives out the intellectual content" (Dickson, 1981). Nonetheless, we expect both a comprehensive understanding of systems and a technical wherewithal from our business students. In the early years of MIS education at Saint Joseph's University, information systems concepts in conjunction with a programming language served as the Introduction to Information Systems course. The students concentrated most of their efforts on the technical nature of the programming language, and ultimately making their programs run properly. Debugging code loomed at the forefront of the introductory course, pushing the system concepts aspect to the wayside as a sub-topic. It was evident that the programming language element severely dominated the course, and in effect, could stand alone as a semester course. Thus, a call for modification intensified.

The redesigned Intro to IS course focused on topics including hardware and software, information systems, an overview of programming languages, and other field innovations. The conceptual material was covered within three fifty-minute classes Monday, Wednesday, and Friday throughout the semester. To supplement the lecture, a hands-on lab appended the course requirements. Students learned and were later tested on their application software skills, specifically Microsoft Office modules in an additional two fifty-minute periods per week. In total, five fiftyminute periods equated to a four-credit Intro to IS course.

In recent years, a laptop inclusion program that was aggressively phased through the business curriculum, further complicating the situation. The Intro to IS course was deemed the focal point for the laptop introduction program throughout the entire business school, thereby, adding another element to the challenge of teaching the introductory course. Now, in addition to combining systems concepts and technical applications, we also assumed the task of teaching actual tactile mastery of the hardware. This new responsibility is fraught with potential pitfalls. 
Effectively handling the hardware and software during real time classroom instruction compounds the original predicament of combining concepts and technical applications creating the possibility for myriad new problems.

Technological advances have necessitated another curriculum modification. The ubiquitous nature of PCs and the increasing computer literacy level of incoming freshman pressured universities to re-evaluate programs and facilities. Universities rewired classrooms, libraries and other facilities to accommodate students in the Internet age. Ultimately, three major improvements were made at our university. First, the Internet is now readily accessible at every seat in the classroom, library, and on-campus housing. Second, the business school curriculum is tailored to incorporate e-Learning. Third, all incoming freshman are required to have laptops. The business school building itself was newly constructed to facilitate the inclusion of technology, at all levels of course development.

\section{E-Learning and Laptops}

We aspire to provide students with a perfect equilibrium of intellectual understanding of information systems use in the business arena as well as technical ability. The question then becomes, what is the most effective way to achieve this balance? The answer is e-Learning. Embracing innovation and new educational methodologies of e-Learning steered us to the current Intro to IS course structure. E-Learning can be defined as:

Education via the Internet, network, or standalone computer. Network-enabled transfer of skills and knowledge. $e$ Learning refers to using electronic applications and processes to learn. e-Learning applications and processes include Web-based learning, computer-based learning, virtual classrooms, and digital collaboration. Content is delivered via the Internet, intranet/extranet, audio or video tape, satellite TV, and CD-ROM (www.learnframe.com).

There are many definitions of e-Learning, but for our purposes we will use the above as it is comprehensive to include all facets of computer assisted learning and assessment. In Intro to IS, we aim to incorporate course web pages, electronic communication channels, multiple presentation media, and computer aided tutorials and assessments, all of which give rise to new pedagogical theories and methods.

Today, our university requires and supports a laptop program for incoming freshman. All students majoring in any of the Business disciplines (including Undecided Business) are required to participate in the Haub School of Business (HSB) Laptop Computer Program. Students in these majors must purchase one of the HSB recommended laptops (p. 11, Saint Joseph's University College of Arts and Sciences and Erivan K. Haub School of Business 2003-2004 Catalog).

To spawn widespread acceptance of this program, many courses in the business curriculum necessitate laptop use in the classroom, and in addition, they integrate the use of web pages for communication and assignments. Upper division classes assume a certain level of technical proficiency, the foundation of which must be provided by Intro to IS.

\section{The Melting Pot of MIS}

"Firstly, there should be a harmony between the technological nature of the subject matter and some of the learning and assessment practices (Dowsing, 1999). The students are expected to be adept at using technology as part of their learning mechanisms, for example our courses have provided web access to course material, lecture notes, assignment specifications and administrative information for quite a few years"(Pain and Le Heron, 2003).

The purpose of Intro to IS is to provide students with a general understanding of the use of computer information systems in daily business practices. The course is taken in the first year for all business majors and serves as a foundation for future application needs in other core areas such as statistics, accounting, and finance. Moreover, the course is the basic underpinning for MIS majors, who will migrate to more technical concentrations of field topics such as database and Visual Basic. 
Intro to IS will unify the theory and practice behind the technology encountered in everyday activities, and make the student feel comfortable with computer hardware. The design of the course is such that three semester exams plus a cumulative final exam comprise seventy-five percent of the total course grade. The lab, which will be explained shortly, focuses on Microsoft Office applications and comprises the remaining twenty-five percent of the total grade.

So, what are the necessary computing needs of freshman business students? The answer is best summarized in a study to determine key end-user computer skills, Jensen Zhao surveyed a number of Fortune 500 companies differentiating between skills "important now" and "important now and toward 2005." Of the corporations surveyed, the report showed findings that,

More than $70 \%$ of the respondents rated the following six hardware skills as being "important now" for business professionals: microcomputer (88\%), keyboard (86\%), mouse (85\%), printer (80\%), modem (71\%), and scanner (71\%)...these six skills were considered as still "important toward 2005."

Regarding operating systems and productivity software skills, more than $80 \%$ respondents perceived the skills of using the five software as both "important now and toward 2005" for business professionals: Windows operating systems, word processing, spreadsheet, database, and presentation software. Among the productivity suites, Microsoft Office was the only one rated as "important now and toward 2005" by the majority of the respondents (Zhao, 2002).

\section{Identifying Key Issues}

We are committed to resolving four key issues surrounding the laptop initiative and classroom technology integration. First, the selected approach should cater to the various levels of technical proficiency of freshman business students. Second, technical elements should be complementary, but intellectual concepts must remain the dominant focus. Third, time should be appropriated both inside and outside of the classroom for lab instruction. Lastly, the educational software used for learning and assessment must be user-friendly and resourceful.

\section{Technical Proficiency}

In a typical freshman class enrolling approximately five hundred business school students, there is a broad spectrum of technical ability. E-Learning techniques enable all students to converge at a point of tactile and practical accomplishment suitable for continuing efforts in the ensuing business school courses.

\section{Balance}

E-Learning techniques combined with traditional class lecture involving theoretical computer concepts yield the desired balance of the intellectual content and technical skills necessary for a student's entrance into advance business courses. Additionally, the lab grade is weighted as one-quarter of the total course grade, which is significant but not the majority.

\section{Time}

Success of the laptop inclusion initiative pivots on in-class lab instruction. Students complete a majority of the lab work outside of class; therefore, the designated in-class sessions must act as a channel for e-Learning beyond the classroom. The lab sessions need to be structured such that the students work diligently and efficiently in class achieving clearly defined objectives for each meeting. If the session is to be deemed valuable, students should leave with an understanding of the software mechanisms, the purpose of the application, and the requirements for which they are responsible.

Effective in-class lab sessions will act as a catalyst to ensure students continue to work aggressively outside the classroom. It is our responsibility as instructors to emphasize the benefits of e-Learning methodologies and keep 
students committed to the goals of the course. The students recognize the elements of trust and responsibility for their education we place upon them. The underlying theme then becomes student-teacher collaboration to achieve understanding and knowledge of the material, regardless of time constraints. They will experience freedom to manage their time, pace, and effort invested. The software tool provides a helpful insight to an individual's strengths and weakness on a particular application, so that students can focus their time on specific areas.

\section{Software Tool}

For our course purposes, we use SimNet XPert Learning from McGraw-Hill Technology Education. The software acts as a tutorial and assessment tool, and provides analogous study guide resources particular to the textbook.

SimNet simulates a Microsoft Office application learning environment online. This virtual platform exemplifies the instance of both synchronous and asynchronous data transmission, which is a concept covered in the lecture segment. The tutorial segment has three distinct educational approaches. The "Teach Me" screen is a written and pictorial explanation of the function at hand. The "Show Me" screen caters to the visual and auditory learner with both a computer generated animation and narration of the function. Lastly, the "Let Me Try" screen presents a tactile element for the student (www.mhhe.com/it/simnetxp).

SimNet also provides communication channels for both the instructor and students. E-mail communication is encouraged, especially on matters concerning lab instruction and assignments. "Students always underestimate the time constraints of instructors' availability when they communicate electronically. Email gives them the impression that they are the only correspondents with the instructor. This can be a problem for large groups of students" (Belanger and Jordan, 1998). Fortunately, in our case, class size is relatively small in comparison, with a maximum of approximately sixty students. At the same time, we emphasize to students the risk of last-minute communications and pending deadlines. E-mails are received in greater mass before the last day of an open exam, and occasionally at obscure hours of the morning from students frantic about software glitches or assignment clarifications.

It is critical that the software chosen as a pedagogical aid be user-friendly. The program simplicity must be such that the students overlook the interface and concentrate on the skill. Complicated software programs or unnavigable interfaces will cause students to lose interest immediately. Program stumbling blocks must be eliminated before the program is introduced to students and programmatic idiosyncrasies must be identified as effortlessly surmountable.

As would be expected, the first semester we used a computer-aided assessment tool unforeseeable problems arose. Incongruities quickly frustrated and discouraged students. Difficulties varied from student to student, while SimNet functioned flawlessly for other students. Concerns about falling behind on assignments and dwindling time stressed the students and faculty both. The first semester could have been looked upon as the beta test for both the software and the technique.

\section{Lab Instruction}

It should be stressed to the students that laptops need not be brought to all classes. This should be clearly emphasized in the course syllabus. The instructors must proact and direct the students to only bring their laptops to class with them on certain class meetings. These sessions must be rehearsed and scripted in order to minimize hardware/software glitches, as well as student frustration that they may cause.

The objectives of the initial lab session center around familiarizing students with computer settings and properties. The students install the SimNet software onto their laptops and log into the course web page. At this point, security settings will need to be adjusted to enable cookies and add trusted sites, as this particular software requires. In addition, instructors must be aware of differing operating systems that will cause slight nuances in the overall instruction. Once logged in, the students may edit their profile, including password and email address. The 
students are then introduced to the program interface, and directed on navigating through the various pages. Furthermore, we demonstrate how and where to access the lessons and subsequent exams that will be posted online.

In order for the e-Learning techniques to be beneficial, instructors must be adequately prepared. Instructors can disarm potential difficulties by solid preparation of the course web page. Ensuring identification of students within the course website and proper planning of lesson and test setup eliminates frustration and confusion met during in-class lab sessions. The possibility exists that students will lose confidence in the software, their abilities, and the instructor, if problems occur and are uncontrolled. Such an incident can be catastrophic to the success of the entire lab component. Minimal prep time will avert radical problems and the loss of valuable time.

In our case, the lab sessions occur on Fridays. The first lab session of the semester occurs on the first Friday after the Add/Drop period, so that students who add MIS 1011 will not miss critical instructions. Included below is a template for the manner in which we have proceeded. Every instructor will have deviations and personalizations suitable to their needs and course requirements.

\section{Microsoft Word}

\section{Skills/Objectives}

- $\quad$ Inserting and Modifying Text

- $\quad$ Creating and Modifying Paragraphs

- $\quad$ Formatting Documents

- $\quad$ Customizing Tables

- $\quad$ Creating and Modifying Graphics

- $\quad$ Managing Documents

- Workgroup Collaboration

- $\quad$ Working with Graphics

We begin with Microsoft Word for several reasons. First, students generally have a basic familiarity of word processing applications from high school. However, it is important that students not be lackadaisical toward the application because of an assumed mastery. Second, many MS Word properties, functions, and commands are universal throughout Microsoft Office applications. Third, MS Word knowledge establishes a good basis on which to build and combat the more difficult and less familiar technicalities of Microsoft Excel, Access, and PowerPoint.

The Word lab session provides in-class time and instruction for students to work on the assigned lessons. The SimNet software allows students to work at their own pace. The lesson clearly indicates the list of required skills, and students may choose to skip over tasks with which they are familiar. Students focus time and effort on learning and understanding new functions and properties, thus expanded their skill set. Again, an underlying objective of the session is to establish comfort with the interface and to resolve any hardware/software glitches. At the conclusion of this in-class lab, students are instructed to complete lessons outside of class. Meanwhile, a practice test is made available on the course web page.

The MS Word exam is typically posted on the course web page approximately five days after the lab, and open for a three-day span. The test counts for one-third of the total lab grade. (As mentioned previously, the lab grade equates to twenty-five percent of the total course grade, thus the Word exam contributes to approximately eight percent of the total course grade.) The students complete the Word assessment online, outside of class. We allot one hour for each test sitting. Within a test, each question may be attempted twice, if the first answer is incorrect. We allow two attempts to complete the exam. Once the student has logged into a test, they will be scored. For this reason, the second exam attempt reconciles accidental exits, frozen screens, or other technical problems encountered. This is the main purpose for the additional attempt; however, if the students are not satisfied with the first grade, they may choose to retake the exam, and we accept the best score. The software design and test setup release scores to students, as well as the instructor managed web site, immediately upon completion of the exam. 


\section{Microsoft Excel}

\section{Skills/Objectives}

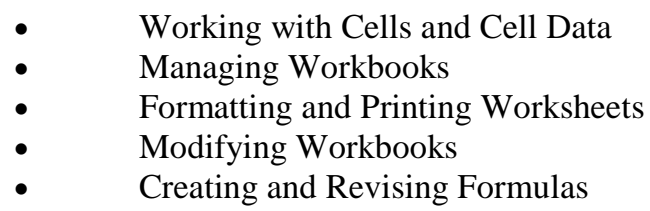

From MS Word, we progress to MS Excel. Due to the vast usage of spreadsheets in other business areas such as statistics, finance, and accounting, we stress the importance of this application and weight it as a third of the lab grade, like Word. At this point in the semester, students fully understand the navigation and usage of the software interface. We post all Excel lessons and practice tests online for students to complete outside of class over two weeks. No in-class lesson time is given for this module, but private help is offered and encouraged.

The Excel assessment is posted on the course web page, but the exam is given in a controlled classroom environment. The students are instructed to bring necessary materials to class, i.e. laptops, network connections, software. As with the Word assessment, the test setup permits an incorrectly answered question to be attempted one additional time. However, the in-class session is the only time the student may access the Excel exam. Make-ups are given at the instructor's discretion.

Attendance is monitored to ensure students identity integrity. The SimNet software randomizes question order for each test. Moreover, the combination of technology and a monitored environment hinders the avenue for cheating (Pain and LeHeron, $\mathrm{p}$ 63). We recognize the simplicity of having someone perhaps more technically adept take the MS Word exam. The opportunity for dishonesty exists because it is accessible online outside the classroom. That said, we contemplated the idea of conducting all applications tests in a proctored environment, but feel that constantly policing the students negates the trust and educational independence we seek to foster. Furthermore, the varying of assessment structure exposes students to possible techniques instructors in other business courses may use.

\section{Microsoft Access}

\section{Skills/Objectives}

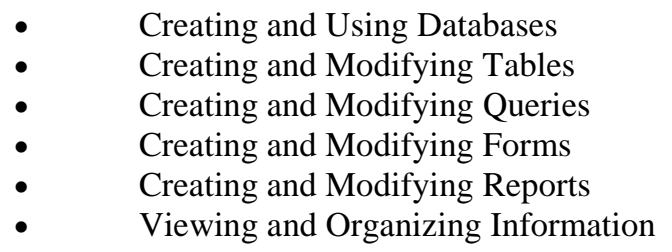

We strive to have the MS Access application coincide with the reading and lecture on databases, because it is typically a hard concept for students to grasp. The lessons and practice test, to be completed outside of class, are available on the course web page subsequent to the Excel assessment, and through the duration of the database lecture days, whenever possible. The required material for Access is limited, and thus the assessment contributes to only one-sixth of the final lab grade. (MS Access is covered extensively in an upper level MIS course.) In a class period before the Access exam is posted, we demonstrate an actual working database and discuss advantages, uses, properties and steps to create basic tables and queries. We also show the ease and benefit of converting an Excel spreadsheet into Access tables and vice versa, specifically pointing to the mobility and manipulation of data. 
The MS Access exam design and setup is identical to the Word exam. Two exam attempts and dual questions attempts are allowed. Each exam grants one hour for completion per sitting, and the test is available online over a three-day span.

\section{MS PowerPoint}

\section{Skills/Objectives}

- $\quad$ Creating Presentations

- $\quad$ Inserting and Modifying Text

- $\quad$ Inserting and Modifying Visual Elements

- $\quad$ Modifying Presentation Formats

- $\quad$ Printing Presentations

- $\quad$ Working with Data from Other Sources

Generally, students have a primitive understanding of MS PowerPoint from high school. Moreover, they have established a solid foundation of Microsoft Office skills at this point in the semester. They have persisted through the technically tough part. We use MS PowerPoint as a relaxed instruction to generate artistic and personal expression. An optional lesson is posted on the course web page, but SimNet is not used for assessment. The students create original presentations upon which their PowerPoint skills are evaluated. The students may work with one other classmate on the presentation, and the required elements are identifying in a handout.

This project is weighted as one-sixth of the total lab grade. As extra incentive, top presentations will receive one hundred points for the PowerPoint grade, and we award extra points on the total grade for the concepts portion of the course. The top presentations are also shown in class. It is our experience that students thoroughly enjoy the relaxed exercise and the opportunity for boosting their overall grade.

We have seen that students typically chose not to use the SimNet software lesson, but rather work directly in the presentation using trial and error methods to learn about the functions and properties of PowerPoint. In addition, the students collaborate on individual projects sharing knowledge and technical competence. They teach one another how to import files, insert music and movie clips, scan pictures, and burn presentations onto CDs. Guidance is offered from the instructor as well, but ultimately, this project reveals the educational independence and technical wherewithal of the students, which we as educators aspire to create. The PowerPoint project is the culmination of joint efforts from both students and instructors.

Ultimately, the PowerPoint presentations are exceptional. Through the presentations, the students exhibit technical capability as well as creative genius. We, as instructors, learn about students' personalities, lives, hobbies, and interests, the personal uniqueness that cannot always be appreciated through classroom interactions. Topics range from sports, television, and music, to jobs and weddings. Occasionally, a good-natured satire of the course and the instructors is amongst the top presentations.

\section{Conclusion}

We alter the learning and assessment structure per application to teach students to manage online assignments both outside of class as well as in controlled classroom settings. Upper division courses differ in the style and usage of technology inclusion in their course requirements. The level of reliance on technology also varies across the business curriculum. The Intro to IS course conscientiously prepares students for all facets of e-Learning. The philosophy and methodologies nurture educational independence but emphasize integrity in conjunction with the university academic honor code.

An introductory information systems course is a pedagogic challenge that puzzles many educators. Systems concepts and theory, technical ability, and a laptop inclusion program initially piece together in an 
awkward fashion. However, technical innovations and new e-Learning methods fuse these complex educational elements into a powerful course from which student emerge professionally adept and technically competent.

\section{References}

1. Belanger, F. and Jordan, D. Cybertools for Instructors: Using the Internet and the World Wide Web to Enhance Learning in the Classroom. Journal of Information Systems Education. Vol.9, No. 1 (Fall 1998), pp.3-9.

2. Dowsing, R. D. (1999). The computer-assisted assessment of practical IT skills. In Brown, S., Race, P. \& Bull, J. (Eds.) "Computer-Assisted Assessment in Higher Education", London: Kogan Page Ltd., 131-138.

3. Pain, D. and Le Heron, J. (2003) WebCT and Online Assessment: The best thing since SOAP? Educational Technology \& Society, 6(2), 62-71, Available at http://ifets.ieee.org/periodicals/6-2/7.html

4. Zhao, Jensen J. Computer End-User Skills Important for Business Professionals Now and Toward 2005. Journal of Computer Information Systems. Spring 2002, pp. 31-37.

5. www.learnframe.com

6. www.mhhe.com/it/simnetxp 